\title{
Processo psicossocial de apropriação pelos frequentadores da Praça Henrique Lage em Imbituba - SC
}

\author{
Psychosocial process of appropriation by the Henrique Lage Square's \\ Goers In Imbituba - SC
}

http://dx.doi.org/10.5007/2178-4582.2016v50n1p149

\section{Rosa Nadir Jerônimo, Carolina De Souza Pittigliani e Jeverson Rogério Costa Reichow}

Universidade do Extremo Sul Catarinense, Criciúma/SC, Brasil

\begin{abstract}
Este artigo resulta de uma pesquisa de conclusão de curso em Psicologia realizada na cidade de Imbituba, Santa Catarina. O estudo teve como objetivo compreender o processo psicossocial de apropriação dos frequentadores da Praça Henrique Lage, a partir do enfoque da Psicologia Ambiental. A pesquisa de abordagem qualitativa refere-se a um estudo de caso composta por seis frequentadores da praça entre 12 e 22 anos. A coleta de dados consistiu na realização de questionário estruturado com questões abertas e fechadas. A análise foi orientada pelas categorias trazidas pelos sujeitos: frequência e relações interacionais; infraestrutura da praça e qualidade de vida; significados psicossociais da praça; processo psicossocial de apropriação. Os resultados apontam que os frequentadores desenvolveram um processo psicossocial de apropriação com o entorno da praça, integrando o espaço físico ao espaço simbólico e afetivo exemplificados nos lugares de encontro, de interação e memórias individuais e coletivas no ambiente urbano de Imbituba.
\end{abstract}

Palavras-chave: Praça; Processo Psicossocial; Apropriação do Espaço.
This article results from a final work of a Psychology course carried out in the city of Imbituba, Santa Catarina. The study aimed to understand the psychosocial process of appropriation by the Henrique Lage square's goers, from the environmental psychology approach. The qualitative research refers to a case study of six subjects between 12 and 22 years. The data collection consisted of structured questionnaire with open and closed questions. The analysis was guided by the categories brought by the individuals: frequency and interactional relationships; square infrastructure and quality of life; psychosocial meanings of the square; psychosocial process of appropriation. The results show that they have developed a psychosocial process of appropriation with the surroundings of the square, integrating the physical space to the symbolic and affective space exemplified by places of encounter, interaction and individual and collective memories in the urban environment of Imbituba.

Keywords: Square; Psychosocial Process; Space Appropriation.

\section{Introdução}

O presente artigo visa compreender o processo psicossocial de apropriação dos frequentadores da Praça Henrique Lage, a partir do enfoque da Psicologia Ambiental. A praça, segundo Souza (2004), desenvolve um importante papel nas relações sociais, pois é um espaço público, livre, que qualquer pessoa pode usufruir para descanso, lazer, ponto de encontro, conversas, relações, interações e integração. Para Yokoo \& Chies (2009), atualmente as praças são constantemente vistas como locais abandonados pela maior parte da população, mas concordam que a praça é uma forma de paisagem presente no cenário 
urbano, representando um elo de apropriação entre o homem e a natureza, entre a população e a cidade.

Segundo Jerônimo e Gonçalves (2013), a apropriação do espaço, na Psicologia Ambiental, envolve uma compreensão multidimensional dos processos psicossociais dos sujeitos com entornos e lugares nos quais possam se identificar, deixar suas marcas e cultivá-los. Deste modo, os processos acima citados incluem as experiências afetivas e cognitivas dos sujeitos com o espaço físico-social e os lugares mais significativos.

Para tanto, este estudo consistiu em problematizar o processo psicossocial de apropriação dos frequentadores da Praça Henrique Lage, recentemente revitalizada, a partir do enfoque da Psicologia Ambiental, buscando compreender como se dá a frequência e as relações interacionais das pessoas com a praça; como a infraestrutura da praça está articulada com a qualidade de vida dos frequentadores; quais os significados psicossociais da praça atribuídos pelos sujeitos, e como se desenvolve o processo psicossocial de apropriação da Praça Henrique Lage por seus frequentadores.

Apesar de consideravelmente recente, a teoria da apropriação do espaço que fundamenta este estudo de Psicologia Ambiental é inegavelmente relevante, não somente no que diz respeito à Psicologia, como em toda área social, pois se preocupa com assuntos que visam buscar alternativas para uma melhor qualidade de vida, com ênfase principalmente no meio urbano.

\section{Psicologia ambiental}

A Psicologia Ambiental apresenta diversos enfoques. Neste artigo destacase o processo de apropriação do espaço do ambiente urbano. Como a Psicologia Ambiental delimita a área de intervenção desta pesquisa, resumidamente, revisita-se seu histórico, já que é uma área de estudo recente no Brasil, surgindo, segundo Tassara e Rabinovich (2003), na década de 1960. Gonçalves (2007) diz que a Psicologia Ambiental, a princípio, teve suas origens na Europa, com forte influência da Ecologia, não derivando somente, então, da área da Psicologia. Complementando os estudos das origens da Psicologia Ambiental, Carneiro e Bindé (1997, p. 364) concluem que a finalidade desse campo de estudo era "uma articulação teórica dos acontecimentos da vida diária". A Psicologia Ambiental foi definida por Nagar (2006) como o estudo das inter-relações do sujeito com o ambiente físico, seja este construído ou natural.

Há seis características básicas que embasam a Psicologia Ambiental, sendo estas, respectivamente, a Gestalt em sua abordagem holística; a inter-relação, trazendo consigo as consequências e análise das relações; a Psicologia 
Social, pois muito da Psicologia Ambiental relaciona-se e deriva-se dela; a interdisciplinaridade, já que esta área de estudo também se inter-relaciona com diversas outras áreas dentro de suas especificidades e em seus diversos campos de atuação; a multimetodologia, visto abranger amplamente numerosos conteúdos, permitindo que a Psicologia Ambiental usufrua de distintas abordagens e metodologias; e, por fim, o último aspecto característico é a pesquisa-ação, que é propriedade de fazer-se valer a pesquisa para fins que contribuam com a sociedade, unindo teoria e prática.

Günther e Rozestraten (2005) estruturaram um artigo em que trazem considerações consistentes sobre as áreas de pesquisa e ensino em Psicologia Ambiental, situando sumariamente o histórico, discutindo definições conceituais e demonstrando que o planejamento das cidades pode se favorecer, em muito, desta área da Psicologia. De acordo com os autores supracitados, a Psicologia Ambiental necessita de pesquisas sobre os "locais que têm impacto benéfico sobre o ambiente, sem perder a vista de que maneira trabalhos locais se inter -relacionam, tanto entre si, tanto com outros lugares" (GÜNTHER; ROZESTRATEN, 2005, p. 6).

Existe imprescindivelmente uma interação entre o indivíduo e o meio-ambiente que, segundo Gonçalves (2007, p.4), é "o local em que o sujeito vive e constrói a sua subjetividade." Desta forma, a relação entre o sujeito e o ambiente, resulta em uma dimensão simbólica, que gera estudos acerca da valorização da paisagem relacionados à qualidade de vida.

As relações estabelecidas vão construindo a integração e a interação do sujeito ao seu ambiente, sendo a marca humana a sua forma de maior expressão. Mediante a ação do sujeito sobre o espaço, Jerônimo e Gonçalves (2013, p. 129) aferem que marcas são incorporadas aos seus elementos psicossoais envolvendo "a cognição, a afetividade, a estética e a linguagem simbólica".

Os elementos processuais acima descritos culminam com a construção da identificação com o lugar que, segundo Pol (1996) e Proshansky (1978), é um componente do processo de apropriação do espaço, implicando na sua posse real ou simbólica. A personificação é a transformação intencional do espaço, onde o sujeito deixa suas marcas, moldando-o as suas necessidades e desejos (SANSOT, 1996). A cultivação, de acordo com Gonçalves (2007), decorre do sentimento de pertença e da identificação com o lugar. Isto ocorre quando o individuo cuida, preserva o espaço, tornando-o aconchegante às suas necessidades individuais e sociais de acordo com seu modo de vida.

A partir da ampla dimensão conceitual que envolve os processos psicossociais chega-se à apropriação do espaço, conceito relevante na Psicologia Ambiental. Portanto, a apropriação do espaço é definida por Jerônimo e Gon- 
çalves (2013) como a expressão singular do reconhecimento dos sujeitos no ambiente, o qual inclui as praças no ambiente urbano ou em comunidades ruro-urbanas.

\section{Praça e espaço público}

Muitas são as definições que podem ser encontradas para o termo "praça", desde o dicionário às interpretações subjetivas e de senso comum, pois por ser um espaço público e de acesso à população, cada indivíduo pode significá-lo de uma forma. Do mesmo modo, podem-se encontrar explicações de diversos autores, que apesar de utilizarem maneiras diferentes para esclarecer o tema, convergem em suas opiniões. Desta forma, utiliza-se a descrição dada por Demattê (1997), que define de forma objetiva e suscinta as praças como pontos de encontro cuja principal função é incentivar a vida comunitária. Entretanto, o autor ressalta que não se pode padronizar a praça sem conhecer antes o seu entorno.

Souza (2004, p. 12) sugere que a praça, além de ser um lugar "de passagem, é um ponto de convergência urbana para diversos grupos"; e continua afirmando que "é lugar de lazer e diversão, assumindo um caráter afetivo", trazendo "bem-estar, tranquilidade e relaxamento" aos frequentadores.

Valadares (2000, p.85) diz que "precisamos conviver, além de sobreviver", referindo-se à necessidade urgente de nos comunicarmos e interagimos com o outro, pois a comunicação é inerente ao ser humano. E é nesse sentido que a praça desenvolve papel importante dentro da sociedade, já que é um espaço público, acessível a toda população. E, neste contexto, surgem também as significações dos lugares.

Quanto ao conceito de significação, Valadares ressalta, ainda, que é no convívio diário das pessoas que são construídos tais espaços e significações. Para o autor, são lugares de encontros, recordações, nostalgia. "São espaços ligados a épocas, a momentos, à infância, à juventude e a conquistas." (Ibid., p. 84)

Jacobi (2003) faz uma crítica a construções de praças que não levam em consideração a cultura local, atribuindo a este fator a razão pela qual estes locais públicos não são povoados dentro da cidade. Além disso, fala sobre a monotonia acerca desses espaços vazios que, por serem padronizados, resultam em um lugar que o autor define como "anticidade".

Jacobi (Ibid.) afirma, ainda, que muitos dos problemas de cunho originalmente urbano, poderiam ser resolvidos caso houvesse um planejamento focado na base cultural dos habitantes do local em questão. Por fim, o autor ressalta a importância do que chama de figura pública autonomeada - que são 
os comerciantes, proprietários de lanchonetes, lojas, padarias que se localizam no local ou em suas proximidades - que gera um fluxo interrupto de pessoas, com as quais aqueles que passam pelo local estabelecem maior confiança.

\section{Materiais e método}

Este estudo foi realizado por meio de pesquisa de campo, com abordagem qualitativa, tendo como método o estudo de caso. A unidade de intervenção foi a Praça Henrique Lage no município de Imbituba, sul de Santa Catarina. A amostra foi composta por seis frequentadores assíduos da praça, tendo como critérios a idade (três adolescentes e três jovens adultos) sem distinção de sexo. Os frequentadores foram observados pela pesquisadora nos três turnos (manhã, tarde e noite) por alguns dias da semana, principalmente aos sábados e domingos num processo de aproximação com o lugar. Após ter definido a amostra pela observação, incluíram-se os adolescentes e os jovens que mais usufruíam da praça. Foi realizado contato verbal com os sujeitos, explicitando os objetivos da pesquisa e solicitando a sua participação.

Os três primeiros frequentadores de cada grupo que aceitaram participar da pesquisa tornaram-se os sujeitos do estudo. Ressalta-se que todos os procedimentos éticos foram observados, desde a escolha dos sujeitos, a apresentação da proposta da pesquisa e assinatura dos Termos de Compromisso que, no caso de menores de 18 anos, foram assinados por seus responsáveis. A todos foi assegurado o direito ao sigilo, anonimato, privacidade e a recusa de participação a qualquer momento, em consonância com as normas do Comitê de Ética em Pesquisa da Universidade do Extremo Sul Catarinense - UNESC ${ }^{1}$.

A coleta de dados teve como principal instrumento um questionário com questões abertas e fechadas, preenchidos pela pesquisadora, mantendo a fala original dos sujeitos nas questões abertas, sendo que nas questões fechadas o sujeito pôde escolher entre duas ou mais alternativas de resposta.

A análise dos dados foi norteada pela proposta de Minayo e Deslandes (2010), baseando-se na compreensão das falas dos sujeitos, integrados em três momentos: o da ordenação dos dados colhidos nos questionários; o da classificação das informações categorizadas de seguinte forma: frequência e relações interacionais; infraestrutura da praça e qualidade de vida; significados psicossociais da praça; processos psicossociais de apropriação; e, por fim, o da análise final, estabelecida na articulação entre os dados coletados e o referencial teórico interdisciplinar em Psicologia Ambiental.

$\overline{1}$ Avaliação e aprovação de acordo com o Protocolo no 246.663. 


\section{A Praça Henrique Lage de Imbituba}

A praça escolhida para esta pesquisa foi a Henrique Lage, localizada na cidade de Imbituba - SC, que, após trinta e cinco anos de sua inauguração, passou por um processo de revitalização no qual foram construídos espaços para entretenimento como a academia ao ar livre, pista de skate, lugar para caminhada, além da restauração do parquinho, atraindo um público maior ao local, interessados em usufruir da praça.

O local é amplo, porém não se localiza em um ponto favorável da cidade, já que se localiza longe do comércio e dos atrativos em geral, como lanchonetes, padaria, livraria, etc.; além de não situar-se estrategicamente em frente à Igreja Matriz, como ocorre na maioria dos outros municípios. A Praça Henrique Lage encontra-se ao lado da Igreja Matriz da cidade, em torno de prédios históricos, onde se localiza também a sede da rádio da cidade e em frente a um supermercado; além disso, há casas e uma escola em sua proximidade, embora não haja um fluxo numeroso de pessoas transitando no local.

Na revitalização da Praça Henrique Lage, optou-se, por meio de debates, por avaliar as necessidades do entorno, arborizar o local com árvores nativas, além de espécies ornamentais e frutíferas, pesquisando opções de plantio de acordo com o porte da árvore, local mais apropriado, tempo de crescimento, funcionalidade, etc; conservando as espécies que já se encontravam no local, como forma de preservar a sua história.

Antes da revitalização a praça não oferecia nenhum tipo de atrativo interno, apenas um parque infantil. Ressalta-se, também, a falta de arborização, o que desfavorecia o espaço público. Desta forma, o espaço que deveria ser apropriado pelos habitantes, passava a maior parte do tempo vazio. Para manter a praça em bom estado, a Secretaria de Administração e Gestão Pública - SEAGP propôs uma equipe fixa de manutenção para realizar serviços como corte de grama e poda de árvores, além dos cuidados gerais.

\section{Apresentação e discussão dos resultados}

Os resultados são apresentados de acordo com as categorias trazidas pelos sujeitos articulando com os objetivos da pesquisa: frequência e relações interacionais; infraestrutura da praça e qualidade de vida; significados psicossociais da praça; processo psicossocial de apropriação.

Durante a observação percebeu-se que a maior parte do público da Praça Henrique Lage são as crianças e jovens devido, principalmente, à existência do parque e à pista de skate. Thompson (2007) separa esses dois grupos, de- 
finindo suas características e conexões com a natureza, além de considerar o local um ponto de encontro de amigos e lazer.

Para Thompson (Ibid.), as crianças relacionam-se muito bem com a natureza e seus aspectos, tais como as plantas e a terra, entre outros e, com o passar dos anos, essas vivências tornam-se ainda mais sofisticadas. Travlou (2007, p. 71) concorda, dissertando que "as crianças têm uma participação positiva e lúdica em relação aos ambientes naturais, porém adolescentes e adultos jovens parecem atravessar uma fase de afastamento em relação à natureza".

Entretanto, percebe-se que durante a história, nem sempre o lazer e entretenimento voltado às crianças tiveram em foco, pois, segundo Marques (2010), não eram considerados tão importantes quanto os demais lugares nos espaços públicos. Somente nos últimos trinta anos começou-se a valorizar os espaços infantis, destinando especialmente áreas públicas para as crianças brincarem, tais como os parquinhos. Dessa forma, compreende-se mais facilmente a queixa de uma das entrevistadas em relação ao parquinho da Praça Henrique Lage, que julga necessário haver mais espaços voltados às crianças.

Já na fase da adolescência, Thompson (2007) menciona o importante papel do ambiente no processo de desenvolvimento da "auto-identidade e independência", por ser este um período em que o indivíduo dá maior ênfase a si mesmo e a seus pares, tendo a tendência de excluir os demais grupos etários de suas experiências. Travlou (2007) complementa a importância do ambiente no desenvolvimento da identidade, considerando que os espaços públicos transformam-se muitas vezes em palco para estes jovens que colocam-se à prova, perante a sociedade e seus pares, em competições e performances.

Sobre este tema, Valadares (2000) discursa a respeito da arquitetura e engenharia das praças que, por serem um ponto de encontro, devem garantir, ao mesmo tempo, liberdade e segurança, para que se tornem convidativas à frequência da população.

Neste sentido, pode-se compreender como a praça influencia o cotidiano dos frequentadores da Praça Henrique Lage, principalmente daqueles que a utilizam com cunho esportivo, como o skate. Além disso, Travlou (2007) ainda menciona outro fator que aparece nas respostas dos sujeitos como: a liberdade que o local traz ao jovem, considerando que passam parte do tempo livre longe de suas casas, com seus amigos, geralmente em locais públicos, concedendo-lhes maior "autonomia, anonimato e liberdade". Esta liberdade é relevante para a frequência e o desenvolvimento das relações interacionais. 


\section{Frequência e relações interacionais}

A frequência dos sujeitos à praça foi relatada como semanal - entre 1 ou mais de 3 vezes - e, mensal, de 3 a 5 vezes ao mês. Um estudo realizado por Libralino (2011) enfatiza que as praças podem ser usadas por pessoas com diferentes faixas etárias e classes sociais, ocorrendo, geralmente, em dias e horários específicos de acordo com as necessidades psicossociais, muitas destas relacionadas ao esporte e ao lazer. Dependendo do mobiliário e equipamentos oferecidos, e presença de sombreamento, as pessoas podem se agrupar e setorizar os ambientes de uso da praça.

De acordo com as entrevistas, a frequência à Praça Henrique Lage ocorre pelas seguintes motivações; a "brincadeira" e a "prática esportiva" (andar de skate e fazer exercícios na academia ao ar livre); "encontrar com os amigos"; assim como para "descansar e se sentir em paz". De acordo com Jerônimo (2012) a frequência das pessoas numa praça, como outros lugares públicos que sejam apropriados pela comunidade, está relacionada ao lugar onde as pessoas se reúnem, conversam, brincam, ou seja, onde há encontro.

Assim sendo, percebe-se que os sujeitos buscam na praça um "ponto de encontro" e "fortalecimento de laços com amigos", além do valor ecológico e subjetivo atribuído a cada um, como a "beleza" e "tranquilidade do local". As respostas dos sujeitos remetem à Jacobs (2000), que lembra que a praça é geralmente um lugar reconhecido pelos sujeitos como um centro; e à Yazigi (2003), que argumenta o valor ecológico, estético e social que são atribuídos às praças, pois é também neste lugar onde as pessoas se aproximam e fortalecem o relacionamento com vizinhos e amigos.

A frequência e as relações interacionais estabelecidas dependem em muito da infraestrutura da praça como um lugar que oferece equipamentos que possam interferir na qualidade de vida de seus frequentadores.

\section{Infraestrutura da praça na qualidade de vida dos frequentadores}

Para melhor entender a interferência dos aspectos físicos da praça, ou seja, da infraestrutura, no bem-estar dos frequentadores se faz necessário compreender o conceito de qualidade de vida inserido no contexto das praças. Gomes e Soares colocam que, a maneira como a qualidade de vida em relação ao meio ambiente é vista, pode ser atribuída à subjetividade de cada indivíduo e sua respectiva percepção sobre ela. Isso quer dizer, que o bem - estar relacionado ao local, depende também do gosto individual de cada sujeito. "A organização dos elementos naturais e artificiais possibilita, através 
do arranjo de diferentes composições paisagísticas, o gosto ou o repúdio ao ambiente" (GOMES; SOARES, 2004, p. 27).

Estes autores ressaltam, porém, que além da estética, a funcionalidade passa pela organicidade da área urbana. Ademais, os autores colocam que, para que um espaço urbano tenha qualidade ambiental satisfatória, é fundamental uma elaboração paisagística que dê ênfase principalmente à vegetação. A vegetação pode ser considerada desde o gramado até as árvores mais corpulentas. Isto é, os aspectos naturais são elementos essenciais na qualidade ambiental; contudo, os demais componentes também se tornam "necessários ao alcance de um padrão mínimo de qualidade do ambiente como os espaços livres públicos destinados ao lazer e a coerência entre os padrões de edificações desse ambiente" (GOMES; SOARES, 2004, p.27).

Os sujeitos da pesquisa revelaram que os aspectos físicos que os levam a frequentar a praça são a "pista de skate" e o "parquinho"; enquanto os motivos interacionais que podem levar à apropriação da praça são: "andar de skate"; "os amigos"; "as pessoas que frequentam"; e, "a paz que tem o lugar". Segundo os sujeitos, em termos de interação social, após a revitalização, o ambiente de relações humanas foi mais favorecido e até melhor apropriado.

Um dos conceitos mais conhecidos da Psicologia Ambiental é, sem dúvida, a apropriação de espaço, classificado, segundo Almeida e Siebra (2008), em primário, secundários e públicos. O território primário é a casa onde o indivíduo vive, enquanto os secundários são os espaços utilizados no cotidiano de maneira constante; já os territórios públicos são as praças, ruas e espaços compartilhados com outras pessoas no geral. Assim reporta-se à importância da apropriação das áreas públicas; mas para que esses espaços sejam apropriados, é necessário que haja lugares adequados. Como visto nas respostas dos sujeitos, na Praça Henrique Lage, há apropriação do parquinho, um local voltado para a diversão das crianças.

Almeida e Siebra $(2008$, p.10) afirmam que a finalidade do parque infantil "é de fortalecer sua autonomia, sua capacidade criadora, sua consciência coletiva, sua solidariedade e sua cooperação" Além disso, brincar, torna-se, além de lazer e entretenimento, um ato de inclusão, socialização e integração, o que pode ser visto principalmente nos parques infantis. Estes autores observam que, nos dias atuais, as grandes cidades contêm poucos espaços reservados para a diversão da criança. Contudo, não basta apenas criar parques sem planejamento, pois é necessário também cuidar da manutenção, segurança dos equipamentos, distância adequada entre brinquedos, entre outros fatores. Desta forma, não apenas os brinquedos propriamente ditos, como equipamentos lúdicos, são essenciais, mas todo o meio que os envolve. "As 
pessoas necessitam de lugares que sirvam para encontrar-se, compartilhar ideias e discutir, lugares como interação com vida" (ALMEIDA; SIEBRA, 2008, p.11).

Já a perspectiva de espaço referente aos skatistas e à pista pode ser visto com mais frequência nas respostas dos adolescentes. Para um maior embasamento no assunto, Dias e Domingues (2011) introduzem o esporte em um pequeno histórico, contando que o mesmo surgiu da prática esportiva.

De acordo com Brandão (2013), o skate desperta nos seus praticantes uma relação diferenciada com a cidade. $\mathrm{O}$ autor afirma que o ponto de encontro da prática do skate passa a ter uma nova interpretação para os adeptos desse esporte. "Os skatistas passaram a projetar sobre seus elementos constitutivos outras funcionalidades que ultrapassavam seus sentidos primeiros, construídos pelos engenheiros, arquitetos e demais pensadores da cidade" (BRANDÃO, 2013, p.12). Ganha, desta forma, um novo significado.

Os sujeitos mostram-se satisfeitos com a praça e sua atual infraestrutura. O que leva cada um a frequentar a praça são razões, predominantemente subjetivas, e dizem respeito tanto à "paz encontrada no local", como por ser um "espaço de encontrar os amigos", principalmente nos lugares bem demarcados como a pista de skate e o parquinho infantil. Cada um percebe e organiza de forma diferente o sentimento em relação à praça.

A satisfação não é plena, apontam para a necessidade de cuidados deste bem comum por parte do poder público. Os sujeitos reforçam o pensamento de Jacobi (2003), que lembra que as praças devem ser construídas e revitalizadas considerando a cultura local, pois para a autora, muitos dos problemas de cunho originalmente urbano, poderiam ser resolvidos caso houvesse um planejamento focado na base cultural dos habitantes do local em questão.

A infraestrutura da Praça Henrique Lage, com seus equipamentos, interfere na qualidade de vida dos frequentadores, ao possibilitar encontros sociais e a prática de esporte, ao mesmo tempo em que colabora com o mundo simbólico e dos significados aos Imbitubenses.

\section{Os significados psicossociais da Praça Henrique Lage}

Entre os frequentadores da Praça Henrique Lage, as respostas mais frequentes sobre o seu significado foram: "lugar de encontro", "lazer" e "tranquilidade". Quanto aos lugares que há identificação com a praça, os sujeitos trouxeram o espaço físico e o espaço afetivo como a "pista de skate", o "coreto", o "parquinho" e até mesmo a "grama". Os lugares trazidos pelos entrevistados remetem à Gonçalves (2007, p. 4), para quem, na Psicologia Ambiental, 
esses espaços se recobrem de um novo sentido, carregados de significados, deixando de ser apenas o meio físico e tornando-se "uma dimensão cultural social que o sujeito internaliza e representa", levando o indivíduo a apropriarse, sentir-se ligado e pertencente ao espaço. Como já visto anteriormente, o conceito de apropriação de espaço engloba diversas dimensões e "se trata de reconverter um espaço distante e estranho em um lugar significativo" (GONÇALVES, 2007, p.6).

Gonçalves (Ibid.) enfatiza um erro comum sobre os monumentos urbanos, referindo-se ao fato de que essas construções terem significados preestabelecidos, que podem não ser apropriados pelos habitantes. Isto se confirma pelas respostas dos sujeitos, uma vez que os entrevistados não citam nenhum dos quatro monumentos que podem ser encontrados na Praça Henrique Lage. "Os monumentos talvez fossem apropriados se os projetos fossem discutidos anteriormente com a comunidade. Assim, poderia haver uma recriação coletiva do significado desses monumentos [...]" (GONÇALVES, 2007, p.6).

Já os sujeitos colocaram os sentimentos e sensações como "liberdade", "felicidade", "alegria", "realização", "bem-estar", "tranquilidade", "sentir-se mais vivo" e de "lazer", ao estarem na praça, o que remete à Psicologia Ambiental, no que diz respeito às dimensões estética e afetiva. Para Morin (2005, p. 133), a estética assemelha-se a "um transe de felicidade, de graça, de emoção", é uma emoção ao estar em contato com algo belo para o sujeito, uma beleza subjetiva. Apesar de comumente relacionada como uma propriedade da arte, a estética não se restringe somente a isso.

Como significados para frequentar a Praça Henrique Lage, os sujeitos trouxeram o "lazer", "um lugar para eu ser eu mesmo", "lugar de encontro e de lembranças" corroborando a pesquisa de Valadares (2000) pelas significações relacionadas aos lugares de recordações e nostalgia. A praça reconduz a pessoa ao contato com a natureza e consigo mesmo. Para Salatino (2001), tal aproximação oferece grandes benefícios tanto para a saúde mental quanto para a saúde física dos cidadãos. Apesar de atualmente já ser observada alguma diferença nas áreas urbanas, principalmente nos bairros mais nobres, que prezam por um ambiente bem arborizado, com ruas amplas e plantas ao longo das calçadas, há muito que evoluir no que diz respeito à valorização da natureza.

Os significados psicossociais dos frequentadores em relação à Praça Henrique Lage perpassam as dimensões subjetivas como a cognição, a estética, a afetividade e a linguagem simbólica (GONÇALVES, 2007; JERÔNIMO, 2012; JERÔNIMO; GONÇALVES, 2013) são características relevantes na construção do processo psicossocial de apropriação do espaço. 


\section{Processo psicossocial de apropriação dos frequentadores da Praça Henrique Lage}

Para este estudo foram trabalhados os processos de identificação com o lugar, personificação do lugar e a cultivação dos frequentadores da Praça Henrique Lage, de acordo com o enfoque da Psicologia Ambiental.

Para o estabelecimento da identidade do indivíduo com o lugar, ou seja, a identidade de lugar, segundo Proshansky (1978), há aspectos do entorno físico que cooperam para consolidá-la, podendo tanto ser de cunho consciente ou mesmo inconsciente. A identificação com o lugar, de acordo com Pol (1996), Proshansky (1978), Gonçalves (2007) e Jerônimo (2012) é parte integrante na apropriação de um espaço, neste caso da Praça Henrique Lage.

Neste sentido, as respostas trazidas pelos entrevistados são expressas na identificação com algumas obras arquitetônicas, como a "igreja" e o "coreto" que, segundo o relato de um sujeito oferecem "uma visão mais ampla da praça"; assim como o "parquinho" evoca as "lembranças da infância". O elementos da natureza, representados pelo "gramado" e pelas "árvores" oferecem bem-estar, pois de acordo com um dos entrevistados, "dá para deitar e refletir".

A personificação do lugar é, de acordo com Sansot (1996), Gonçalves (2007) e Jerônimo (2012), a transformação de um espaço onde o sujeito deixa suas marcas, deixando nele um pouco de si mesmo. A personificação do lugar pode ser observada principalmente na "pista de skate", onde há muitos "grafites". Algumas das palavras escritas na pista como: "acredite", "overdose" e referências às contas de redes sociais das pessoas que frequentam o local. No "coreto" também foi possível perceber muitas marcas de personificação, que indicam a possibilidade de ser de outro (s) grupo (s), uma vez que os símbolos representados são diferentes, como "pentagramas", "desenhos", "iniciais e nomes de pessoas". Jerônimo e Gonçalves (2013) enfatizam que as marcas deixadas pelos sujeitos em um espaço, manifestam sua subjetividade e afetividade ao lugar.

A cultivação nascida dos processos anteriores é exemplificada no cuidado e na preservação que o sujeito e a comunidade têm com o lugar, tornando-o propício às necessidades individuais e coletivas, segundo Gonçalves (2007). De acordo com os sujeitos, a praça é um lugar de encontro, de esporte, de recordações, de descanso, e, para que este lugar mantenha estes sentidos, é necessário cultivá-lo, construindo o telhado no coreto, mantendo o gramado cortado e a rede elétrica em condições de se usufruir do espaço também à noite com segurança.

A apropriação do espaço, na Psicologia Ambiental, segundo Gonçalves (2007) e Jerônimo (2012) estuda o simbolismo do espaço, como se constroem 
os processos psicossociais derivados das relações e interações entre as pessoas e os ambientes. Compreende-se que os frequentadores da Praça Henrique Lage identificam-se com o lugar, personificam alguns lugares e, em suas respostas, buscaram mobilizar o poder público para a cultivação da mesma. Assim, considera-se que os processos psicossociais de apropriação como identificação, personificação e cultivação se fazem presentes nos comportamentos dos frequentadores da Praça Henrique Lage.

\section{Considerações finais}

O tema central do artigo versou sobre a compreensão do processo psicossocial de apropriação pelos frequentadores da Praça Henrique Lage em Imbituba - SC. A pesquisa surgiu da observação de que a praça não possui um fluxo contínuo de pedestres, apesar de ter visivelmente aumentado o número de frequentadores após uma revitalização total que contou com a implementação de uma academia ao ar livre, pista de skate e renovação do parquinho infantil. Visando maior contato com a natureza, e sombra para aqueles que buscam o descanso e lazer na praça, novas árvores foram plantadas, objetivando um local bem arborizado. Para garantir a segurança, mesmo durante $o$ período noturno, houve investimento na iluminação.

A pesquisa permitiu identificar dois tipos de público da praça: primeiro, aqueles que já frequentavam o local antes de sua revitalização; e aqueles que começaram a utilizar os lugares da praça somente após a sua restauração. Os frequentadores mais antigos relatam que a praça é ponto de encontro de amigos, um lugar tranquilizador e que traz bem-estar. Alguns dos frequentadores antigos da Praça Henrique Lage já costumavam usufruir do local antes mesmo do projeto de revitalização; sendo assim, buscam um lugar tranquilo para se entreterem e descansarem.

Porém, constatou-se que após a revitalização da praça um público mais jovem, sentiu-se motivado a frequentar o local, seja para descansar ou como passatempo, bem como usufruir de um lugar específico, como a academia, parque ou pista de skate, já que o espaço mais amplo e arborizado permite desenvolver diversas atividades, melhorando o clima além de proporcionar sombra para os frequentadores. Além disso, as opiniões se dividiram em relação aos resultados da revitalização, uma vez que alguns pensam ser relevante a praça ter maior público e fluxo de pessoas, enquanto outros discordam, preferindo um local menos frequentado.

De acordo com o Plano Diretor (2010), o município de Imbituba apesar de possuir grande área verde preservada, poucas delas são de uso público, 
ou mesmo equipadas para o lazer dos munícipes. Visualiza-se, segundo o documento supracitado, o grande potencial do município para a instalação de parques e praças, algumas públicas, outras privadas, sendo estas passíveis de agregar valor à paisagem urbana e de promover infraestrutura social à cidade de Imbituba.

No levantamento sobre as praças públicas situadas no município Imbitubense, foi encontrada a existência de onze delas no município, equipadas com meio-fio, iluminação e canteiros com grama, entre estas se encontra a Praça Henrique Lage. Observa-se uma maior concentração de praças na área central de Imbituba havendo algumas em outros núcleos da ocupação da cidade. Entre as principais, destaca-se a Praça Henrique Lage.

Referente aos frequentadores adolescentes, estes buscam na praça um lugar mais específico, como o parquinho infantil ou a pista de skate e, além de considerá-la um ponto de lazer e diversão, a conceituam também como ponto de encontro de amigos e grupos.

$\mathrm{Na}$ fase de observação deste estudo foi possível verificar que a praça é apropriada, prioritariamente, por um público jovem. Uma das dúvidas que permanece é por que o local ainda não é tão frequentado quando supostamente deveria ser? Uma hipótese é a de que o local, mesmo sendo amplo, não se localiza em um ponto favorável da cidade. Além de não situar-se estrategicamente em frente à Igreja Matriz, como ocorre na maioria dos outros municípios, está localizado longe do comércio e de outros atrativos, como lanchonetes, padaria, livraria, etc.

Vale verificar esta questão com maior profundidade pois, de acordo com o Plano Diretor da Cidade de Imbituba (2010), os espaços públicos verdes urbanos são importantes, não apenas pelo aspecto ambiental, mas principalmente como espaços de trocas sociais essenciais em uma cidade. Além disso, a presença de praças e parques dá um sentido de identidade e de referências locais. Isso se percebeu durante a condução da pesquisa, em que os frequentadores puderam revelar que o processo psicossocial de apropriação com o entorno da Praça Henrique Lage integra o espaço físico e o espaço simbólico exemplificados nos lugares de encontro, de interação e de memórias individuais e coletivas no ambiente urbano de Imbituba.

Por fim, sugere-se mais pesquisas abrangendo um número maior de frequentadores da Praça Henrique Lage, em diferentes épocas do ano, já que a praia se localiza bem próxima, com técnicos responsáveis pelos espaços verdes e de lazer públicos da cidade. Há de se pensar também em pesquisas com os grupos grafiteiros, que escrevem seus nomes e endereços das redes sociais e com aqueles que marcam os monumentos, equipamentos com símbolos bastan- 
te instigantes, com o objetivo de conhecer seus significados e o que estes grupos revelam sobre a Praça Henrique Lage, onde transitam, ocupam ou se apropriam.

\section{Referências}

ALMEIDA, Lucia Maria G.; SIEBRA, Marcos Teodorico P. de. Apropriação dos espaços públicos destinados (ou não) ao lazer infantil em um bairro residencial de Barcelona. In: CONGRESSO INTERNACIONAL EM ESTUDOS DA CRIANÇA, 1, fevereiro 2008, Braga, Portugal. Anais. Universidade de Minho-IEC, 2008. Disponível em: $<$ http://www.labrinjo.ufc.br/ phocadownload/apropriaao $\% 20$ dos $\% 20$ espaos $\% 20$ pblicos $\% 20$ destinados $\% 20$ ou $\% 20$ nao $\% 20$ ao $\% 20$ lazer $\% 20$ infantil $\% 20 \mathrm{em} \% 20$ um $\% 20$ bairro $\% 20$ residencial $\% 20 \mathrm{de} \% 20$ barcelona.pdf $>$ Acesso em: 03 dez. 2014.

BRANDÃO, Leonardo. Da Cidade Transfigurada à Cidade Transformada: Culturas Juvenis e a Prática do Skate (1970/1980) Revista História e Cultura, Franca-SP, v.1, n.2, p.7-20, 2013. Disponível em: http://periodicos.franca.unesp.br/index.php/historiaecultura/article/view/734/717 Acesso em: 03 dez. 2014.

CARNEIRO, Clarisse, BINDÉ, Pitágoras J. A Psicologia Ecológica e o estudo dos acontecimentos da vida diária. Estudos de Psicologia, Rio Grande do Norte, v. 2, n. 2, p.277-285, 1997. Disponível em: $<$ http://www.scielo.br/pdf/epsic/v2n2/a10v02n2.pdf $>$ Acesso em 03 Dez. 2014.

DEMATTÊ, Maria Esmeralda Soares Payão. Princípios de paisagismo. Jaboticabal: Funep, 1997. 104p.

DIAS, Mariana Andreotti; DOMINGUES, Áquila Maris. Agregação do espaço urbano por jovens skatistas de Curitiba. SIMPURB- SIMPÓSIO NACIONAL DE GEOGRAFIA URBANA - CIÊNCIA E TECNOLOGIA, 13, Belo Horizonte, 2011. Disponível em: < $\underline{\text { http://xiisim- }}$ purb2011.com.br/gt05/mariana aquila.pdf $>$ Acesso em 25 Mai. 2013.

NAGAR, Dinesh. Environmental psychology. 2 ed. Nova York: Concept Publishing Company. 2006. 390 p.

GÜNTHER, Harmut; ROZESTRATEN, Reinier J. A. Psicologia Ambiental: algumas considerações sobre sua área de pesquisa e ensino. Textos de Psicologia Ambiental, n. 10. Instituto de Psicologia, Laboratório de Psicologia Ambiental, Universidade de Brasília, 2005. Disponível em: <http://www.psi-ambiental.net/pdf/10PsiAmbiental.pdf> Acesso em: 10 fev. 2015.

GOMES, Marcos Antônio Silvestre; SOARES, Beatriz Ribeiro. Reflexões sobre qualidade ambiental urbana. Estudos Geográficos. Rio Claro, v. 1, n. 1, p. 21-30, 2004. Disponível em: $<$ http://www.cchla.ufrn.br/geoesp/arquivos/artigos/ArtigoAmbienteQualidadeAmbientalUrbana.pdf $>$ Acesso em: 11 nov. 2014

GONÇALVES, Teresinha M. Cidade e poética - Um estudo de psicologia ambiental sobre o meio urbano. Injuí-RS: Unijuí, 2007. 204p.

JACOBI, Pedro. Educação ambiental, cidadania e sustentabilidade. Cadernos de Pesquisa, São Paulo: USP, n. 118, p. 189-205, mar. 2003. Disponível em: $<$ http://www.scielo.br/pdf/cp/ n118/16834.pdf>. Acesso em: 24 jun. 2012.

JACOBS, Jane. Morte e vida de grandes cidades. São Paulo: Martins Fontes, 2000. 528p. 
JERÔNIMO, Rosa Nadir T. Cultura e natureza em Ibiraquera: poesia e conflitos numa comunidade tradicional. Criciúma: EDIUNESC, 2012. 247p.

JERÔNIMO, Rosa Nadir T.; GONÇALVES, Teresinha M. Identidade e Personificação do Lugar na Apropriação do Espaço pelos Nativos de Ibiraquera, SC. Revista de Ciências Humanas, Florianópolis, v. 47, n. 1, p. 117-132, abr. 2013. Disponível em: < $\underline{\text { https://periodicos.ufsc.br/ }}$ index.php/revistacfh/...2013v47n1p117/26180>Acesso em: 03 dez. 2014.

LIBRALINO, Cíntia C. Praça: lugar de lazer: relações entre características ambientais e comportamentais na praça Kalina Maia. 2011, 131f. Dissertação (Mestrado em Psicologia). Universidade Federal da Bahia, Faculdade de Filosofia e Ciências Humanas, Natal, RN, 2011. Disponível em: <http://www.repositorio.ufrn.br:8080/jspui/bitstream/123456789/17518/1/ CintiaCL_DISSERT.pdf > Acesso em: 09 fev. 2015.

MARQUES, Reginalice de L. "Posso brincar também?" brincadeiras e contatos sociais no parquinho público. 2010, 149 f. Dissertação (Mestrado em Psicologia). Universidade Federal da Bahia, Faculdade de Filosofia e Ciências Humanas, Natal, RN, 2010. Disponível em: $<\underline{\text { http:// }}$ www.pospsi.ufba.br/Reginalice_Marques.pdf > Acesso em: 05 fev. 2015.

MINAYO, Maria Cecília de S.; DESLANDES, Sueli F. Pesquisa social: teoria, método e criatividade. $31^{\mathrm{a}}$ ed. Petrópolis: Vozes, 2010. 107p.

MORIN, Edgar. $O$ método 5: a humanidade da humanidade a identidade humana. 3 ed. Porto Alegre: Sulina, 2005. 309 p.

PREFEITURA MUNICIPAL DE IMBITUBA. Plano Diretor De Imbituba. Imbituba, SC: 2010. Disponível em: <http://www.imbituba.sc.gov.br/f/planodiretor/CODESC F3 IMBITUBA/CODESC_F3_IMBITUBA_TEXTOS/CODESC_F3_IMBITUBA_PROP̄OSTAS.pdf $>$ Acesso em 04 Dez. 2012.

POL, Enric. La apropiación del espacio. In: INIGUEZ, Lupicínio; POL, Enric. (Orgs). Cognición, representación y apropiación del espacio. Barcelona: Universitat Barcelona Publicacions, 1996. p. 45-60.

PROSHANSKY, Harold M. Apropiación et non apropiación (mis-appropiation) de l'espace. [S.1., S.n.], 1978.

SALATINO, Antonio. Nós e as plantas: ontem e hoje. Revista Brasil. Bot., São Paulo, v.24, n.4 (suplemento), p.483-490, dez. 2001. Disponível em: < < $\underline{\text { http://www.scielo.br/pdf } / \mathrm{rbb} /}$ v24n4s0/9469.pdf> Acesso em: 05 out. 2013.

SANSOT, Pierre. Poétique de la Ville. $6^{\text {a }}$ Reimpressão. Paris: Armand Colin, 1996. 422p.

SOUZA, Bernadete de Lourdes Q. A praça André de Albuquerque, Natal/RN, na visão de seus frequentadores. 94f. Dissertação (Mestrado em Psicologia). Universidade Federal do Rio Grande do Norte. Centro de Ciências Humanas, Letras e Artes. Programa de Pós- Graduação em Psicologia, Natal, RN, 2004. Disponível em: < http://www.natal.rn.gov.br/bvn/publicacoes/bernardetelqs.pdf $>$ Acesso em: 10 fev. 2015.

TASSARA, Eda Terezinha de O.; RABINOVICH, Elaine P. Perspectivas da Psicologia Ambiental. Estudos de Psicologia, São Paulo: USP, v.8, n. 2, p. 339-340, 2003, Disponível em: $<$ http://www.scielo.br/pdf/epsic/v8n2/19052.pdf> Acesso em: 12 out. 2014. 
THOMPSON, Cody Ward. Playful nature. In: THOMPSON, Cody Ward. ; TRAVLOU, Penny. (Orgs) Open space: people space. Nova York: Taylor \& Francis, 2007, p. 6-37

TRAVLOU, Penny. Mapping youth spaces in the public realm. In: THOMPSON, Cody Ward. TRAVLOU, Penny. (Orgs) Open space: people space. Nova York: Taylor \& Francis, 2007, p. 71-81.

VALADARES, Jorge de Campos. Qualidade do espaço e habitação humana. Ciênc. saúde coletiva, Rio de Janeiro, v. 5, n. 1, 2000. Disponível em: <http://www.scielo.br/scielo.phpscrip-

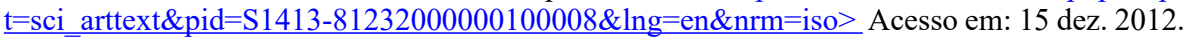

YAZIGI, Eduardo. Patrimônio ambiental urbano: refazendo um conceito para o planejamento urbano. In: CARLOS, Ana Fani; LEMOS, Amália Inês (Orgs). Dilemas urbanos: novas abordagens sobre a cidade. São Paulo: Contexto, 2003, p. 253 - 265.

YOKOO, Sandra C.; CHIES, Cláudia. O papel das praças públicas: estudo de caso da Praça Raposo Tavares na cidade de Maringá. In: EPCT - ENCONTRO DE PRODUÇÃO CIENTÍFICA E TECNOLÓGICA, 4, Campo Mourão, 2009. Anais... Núcleo de Pesquisa Multidisciplinar, Campo Mourão 2009. Disponível em: <http://www.fecilcam.br/nupem/anais iv epct/PDF/ ciencias_exatas/12_YOKOO_CHIES.pdf $>$ Acesso em: 04 set. 2012.

Submissão em: 13/12/2014

Revisão em:20/09/2015

Aceite em: 25/09/2015

Agência de fomento: Universidade do Extremo Sul Catarinense - UNESC

Rosa Nadir Jerônimo é licenciada e Bacharel em Psicologia pela Universidade do Sul de Santa Catarina - UNISUL, especialista em Saúde da Família pela UNISUL. Mestre em Ciências Ambientais pela Universidade do Extremo Sul Catarinense UNESC. Professora titular da UNESC nos cursos de Psicologia e Arquitetura. Tem experiência na área de Psicologia, com ênfase em Psicologia Social e Ambiental. Endereço para correspondência: Rua Rosita Danovith Finster, 990. Criciúma/SC.

CEP: 88804-800.

E-mail: $\underline{\text { rnj@unesc.net }}$

Carolina de Souza Pittigliani é psicóloga pela Universidade do Extremo Sul Catarinense.

E-mail: carolinapittigliani@ibest.com.br

Jeverson Rogério Costa Reichow é psicólogo, graduado pela Universidade Católica de Pelotas e Mestre em Educação pela Universidade Federal do Rio Grande do Sul. Doutorando em Psicologia Social no Instituto de Psicologia da Universidade de São Paulo. Professor da Universidade do Extremo Sul Catarinense, membro do InterPsi - Laboratório de Pesquisa em Psicologia Anomalística e Processos Psicossociais do Instituto de Psicologia da USP. Coordena o GRUPPA - Grupo de Pesquisa em Psicologia Anomalística e Processos Psicossociais da UNESC. E-mail: jrr@unesc.net 